\title{
Prognostic Value of CD56 Expression in Multiple Myeloma
}

\author{
Salah M. Khallaf ${ }^{1}$, Eman A. Yousof ${ }^{2}$, Eman H. Ahmed ${ }^{2}$, Shymaa G. Mansor ${ }^{2}$, Hanan O. \\ Mohamed $^{3}$, Sahar Elgammal ${ }^{3}$, Sawsan M. Moeen ${ }^{4}$, Doaa M. Sayed ${ }^{2}$
}

${ }^{1}$ Medical Oncology Department, South Egypt Cancer Institute, Assiut University, Assiut, Egypt; ${ }^{2}$ Clinical Pathology Department, South Egypt Cancer Institute, Assiut University, Assiut, Egypt; ${ }^{3}$ Clinical Pathology Department, Faculty of Medicine, Assiut University, Assiut, Egypt; ${ }^{4}$ Internal Medicine Department, Clinical Hematology Unit, Faculty of Medicine, Assiut University, Assiut, Egypt.

Background: Understanding the prognostic markers of multiple myeloma (MM) helps in optimizing therapeutic approaches. CD56 is frequently expressed by malignant plasma cells and its use as a prognostic marker in MM is promising. Aim: To evaluate prognostic value of CD56 expression in patients with MM.

Methods: This study included 50 newly diagnosed patients with MM. Bone marrow samples were analyzed for CD56 expression by flow cytometry. All patients received bortezomib-based therapy for at least 3-4 months.

Results: The median age of patients was 52 years (range 32-75) and 54\% of them were males. The stage according to the International Staging System was I in $15(30 \%)$ patients, II in $18(36 \%)$ and III in $17(34 \%)$. CD56 positivity was detected in $84 \%$ of enrolled patients. Multivariate analysis revealed that the lack of CD56 expression was an independent predictor of worse overall survival (HR $=4.31$ [95\% Confidence Interval: $1.23-15.13$ ], $\mathrm{p}=0.002$ ).

Conclusion: The present study suggests that CD56 negativity is associated with poor prognosis in patients with MM and that its incorporation in the risk panel of MM may be considered. Further studies with larger sample size to validate its prognostic value are needed.

Keywords: Multiple myeloma, Flow cytometry, CD56, Prognosis.

Corresponding author: Salah M. Khallaf, M.D.; Department of Medical Oncology, South Egypt Cancer Institute, Assiut University, Assiut, Egypt; Email: salahmab76@yahoo.com

Submitted: 26-February-2020, Revised: 15-March-2020, Accepted: 21-March-2020, Published online: 28-March-2020

(cc) BY

\section{INTRODUCTION}

Multiple myeloma (MM) is a B-cell clonal disease that causes accumulation of malignant plasma cells (PCs) in the bone marrow. This accumulation leads to bony lesions as well as increased levels of serum and urinary monoclonal proteins. Patients with MM may develop hypercalcemia, anemia or renal insufficiency ${ }^{1}$.

Flow cytometric immunophenotyping is important in MM for the diagnosis, predicting prognosis and monitoring treatment ${ }^{2-4}$. Multiparameter flow cytometry (MFC) is a valid method in the fast recognition of clonality criterion of the cells and their aberrant expression of antigens ${ }^{5}$. For a case of MM, the required antibodies panel reported by the European Myeloma Network is CD38, CD138, CD19, CD45, CD56, CD20, CD117, CD28, and CD27. It recommends a minimum of five initial gating parameters (CD38, CD138, CD45, FSC, and SSC properties) within the same tube for the calculation of total plasma cells ${ }^{6}$.

CD56 (neural cell adhesion molecule) is a membrane glycoprotein which is expressed frequently by malignant plasma cells, but not normal plasma cells ${ }^{7-8}$. In recent years, some studies assessed the relationship between MM prognosis and the expression of CD56 ${ }^{9-11}$. Pan et al retrospectively assessed the importance of CD56 as a prognostic factor in 50 newly diagnosed MM patients ${ }^{11}$. They found that patients with CD56 expression had a better overall response rate $(\mathrm{p}=0.024)$. In addition, in multivariate analysis, CD56 positivity was associated independently with longer overall survival (OS) $(\mathrm{p}=$ $0.012)^{11}$.

In this study, we examined the relationship between CD56 expression by malignant plasma cells in newly diagnosed MM patients and clinical as well as laboratory parameters to determine its prognostic value.

\section{METHODS}

This retrospective study included 50 patients with MM who had been treated during an 8-year period (from January 2010 to December 2017) at the Medical Oncology Department, South Egypt Cancer Institute. The study was approved by the Ethical Committee, Assiut University.

The International Myeloma Working Group (IMWG) 12 criteria was used for the diagnosis of MM and the Revised International Staging System (R-ISS) ${ }^{13}$ for its staging. All patients received bortezomib-based therapy that included bortezomib/cyclophosphamide/ dexamethasone for at least 3 months.

Complete blood picture (using Cell-Dyn 3500C S, Abbott Diagnostics, USA), serum chemistry including creatinine, calcium, albumin and $\beta 2$ microglobulin (using COBAS Integra 400 Plus, Roche, Switzerland) and serum protein electrophoresis (using Pretty Interlab, Interlab, 
Italy) were performed for all patients. Bone marrow aspiration (BMA) and biopsy (BMB) and immunophenotyping data were also obtained. Immunophenotyping was performed with a panel of monoclonal antibodies: anti-CD38-fluorescence Isothiocyanate (FITC) conjugated, anti-CD56allophycocyanin (APC) conjugated (Beckman Coulter, Germany), anti-CD138-phycoerythtin (PE) conjugated, anti-CD19- peridinin chlorophyll protein (PerCP) conjugated, anti-Kappa light chain-FITC conjugated and anti-Lambda light chain-PE conjugated (BD Bioscience, USA).

The Statistical Package for Social Science (SPSS) version 21 (IBM, New York, USA) was used for storing, manipulation, interpretation of collected data. Continuous data was presented as mean and standard deviation (SD) or median and range, while categorical data was presented as frequency and percentage. $C h i^{2}$-test and ANOVA tests were used to calculate the relation between the nominal data of two different groups and more than two groups respectively. Overall survival was calculated from the date of diagnosis to the date of death. Censored patients were those alive at last encounter, whether still under regular follow up or lost to follow up. Kaplan-Meier method was used to estimate survival and Log-rank test to identify the significance of the difference in survival between groups in univariate analysis. We examined the prognostic factors in the multivariable analysis using Cox proportional hazards model to test their independent significance. P-value less than 0.05 was considered significant.

\section{RESULTS}

The demographics and baseline characteristics of the enrolled 50 patients are shown in Table 1.

In all cases, plasma cells could be sufficiently identified through CD138 positive gating on mononuclear cells. CD56 was positive in the majority (84\%) of patients.

Table 2 shows a comparison between CD56 positive and CD56 negative patients. There was no significant difference in the studied variables according to CD56 expression status.

After a median follow up period of 24.5 months (1084 months), the median OS of all patients was 30 months (95\% CI 24.54 - 35.46) as shown in Figure 1.

Univariate analysis of overall survival is illustrated in table 3. Overall survival was significantly shorter in patients with negative CD56 disease compared to those with positive CD56 (Figure 2). In addition, advanced stage, renal impairment and higher B2 microglobulin level were associated with significantly shorter OS (Table 3 ). The remaining studied factors did not show a significant correlation.

In multivariate analysis, negative CD56 expression was an independent predictor of worse OS (Table 4). Renal impairment was independently associated with worse OS as well.
Table 1: Demographics and baseline characteristics of 50 patients with multiple myeloma

\begin{tabular}{|c|c|c|}
\hline \multicolumn{3}{|l|}{ Characteristic } \\
\hline & Median & Range \\
\hline \multirow[t]{2}{*}{ Age (years) } & 52 & $32-75$ \\
\hline & No. & $\%$ \\
\hline \multicolumn{3}{|l|}{ Sex } \\
\hline Males & 27 & 54 \\
\hline Females & 23 & 46 \\
\hline \multicolumn{3}{|l|}{ Stage } \\
\hline $\mathrm{I}$ & 15 & 30 \\
\hline II & 18 & 36 \\
\hline III & 17 & 34 \\
\hline \multicolumn{3}{|l|}{ Anemia } \\
\hline yes & 28 & 56 \\
\hline No & 22 & 44 \\
\hline \multicolumn{3}{|l|}{ Hypercalcemia } \\
\hline yes & 21 & 42 \\
\hline No & 29 & 58 \\
\hline \multicolumn{3}{|l|}{ Renal impairment } \\
\hline yes & 13 & 26 \\
\hline No & 37 & 74 \\
\hline \multicolumn{3}{|l|}{ Albumin $(\mathrm{gm} / \mathrm{L})$} \\
\hline$\geq 35$ & 18 & 36 \\
\hline$<35$ & 32 & 64 \\
\hline \multicolumn{3}{|l|}{ B2 microglobulin (mg/L) } \\
\hline$\geq 3.5$ & 36 & 72 \\
\hline$<3.5$ & 14 & 28 \\
\hline \multicolumn{3}{|l|}{ CD56 expression } \\
\hline Positive & 42 & 84 \\
\hline \multirow[t]{2}{*}{ Negative } & 8 & 16 \\
\hline & Mean & SD \\
\hline White blood cells count $\left(10^{9} / \mathrm{L}\right)$ & 8.28 & 4.46 \\
\hline Platelets count $\left(10^{9} / \mathrm{L}\right)$ & 218.44 & 83.41 \\
\hline Hemoglobin level (gm/dL) & 9.72 & 1.66 \\
\hline BMA plasma cell $(\%)$ & 29.50 & 19.13 \\
\hline BMB plasma cell $(\%)$ & 52.12 & 20.6 \\
\hline
\end{tabular}

BMA: Bone marrow aspirate; BMB: Bone marrow biopsy; SD: Standard deviation

\section{DISCUSSION}

CD56 is a homophilic binding glycoprotein implicated in cell-cell adhesion that is involved in attaching plasma cells to the stromal structure of the bone marrow ${ }^{1}$. The prevalence of CD56 positivity in MM varied among studies ${ }^{11,14-16}$. In the current study, $84 \%$ of patients were CD56 positive, which is much higher than the $42 \%$ prevalence found by Boshnak and Hashem ${ }^{14}$. Other studies done by Pan et al ${ }^{11}$, Qiu et al ${ }^{15}$ and Shim et al ${ }^{16}$ reported a prevalence of $71 \%, 61 \%$ and $66 \%$; which is not much lower than that in our study. 
Table 2: Relation between CD56 expression status and baseline characteristics

\begin{tabular}{|c|c|c|c|}
\hline Characteristic & $\begin{array}{l}\text { Positive } \\
\text { CD56 } \\
(n=42) \\
\end{array}$ & $\begin{array}{l}\text { Negative } \\
\text { CD56 } \\
(\mathrm{n}=8) \\
\end{array}$ & $\begin{array}{l}\text { p- } \\
\text { value }\end{array}$ \\
\hline & No. $(\%)$ & No. $(\%)$ & \\
\hline \multicolumn{4}{|l|}{ Age (years) } \\
\hline$<65$ & $37(88.1)$ & $6(75)$ & \multirow[t]{2}{*}{0.31} \\
\hline$\geq 65$ & $5(11.9)$ & $2(25)$ & \\
\hline \multicolumn{4}{|l|}{ Sex } \\
\hline Male & $23(54.8)$ & $4(50)$ & \multirow[t]{2}{*}{0.552} \\
\hline Females & $19(45.2)$ & $4(50)$ & \\
\hline \multicolumn{4}{|l|}{ Stage } \\
\hline $\mathrm{I} / \mathrm{II}$ & $28(66.7)$ & $5(62.5)$ & \multirow[t]{2}{*}{0.558} \\
\hline III & $14(33.3)$ & $3(37.5)$ & \\
\hline \multicolumn{4}{|l|}{ Anemia } \\
\hline Yes & $23(54.8)$ & $5(62.5)$ & \multirow[t]{2}{*}{0.498} \\
\hline No & $19(45.2)$ & $3(37.5)$ & \\
\hline \multicolumn{4}{|c|}{ Thrombocytopenia } \\
\hline Yes & $33(78.6)$ & $5(62.5)$ & \multirow[t]{2}{*}{0.287} \\
\hline No & $9(21.4)$ & $3(37.5)$ & \\
\hline \multicolumn{4}{|l|}{ Hypercalcemia } \\
\hline Yes & $17(40.5)$ & $4(50)$ & \multirow[t]{2}{*}{0.451} \\
\hline No & $25(59.5)$ & $4(50)$ & \\
\hline \multicolumn{4}{|c|}{ Renal impairment } \\
\hline Yes & $11(26.2)$ & $2(25)$ & \multirow[t]{2}{*}{0.659} \\
\hline No & $31(73.8)$ & $6(75)$ & \\
\hline \multicolumn{4}{|c|}{ Hypoalbuminemia } \\
\hline Yes & $15(35.7)$ & $3(37.5)$ & \multirow[t]{2}{*}{0.609} \\
\hline No & $27(64.3)$ & $5(62.5)$ & \\
\hline \multicolumn{4}{|c|}{$\begin{array}{l}\text { B2 microglobulin } \\
(\mathrm{mg} / \mathrm{L})\end{array}$} \\
\hline$\geq 3.5$ & $30(71.4)$ & $6(75)$ & \multirow[t]{2}{*}{0.604} \\
\hline$<<3.5$ & $12(28.6)$ & $2(25)$ & \\
\hline \multicolumn{4}{|l|}{ Bony lesions } \\
\hline Yes & $31(73.8)$ & $6(75)$ & \multirow[t]{2}{*}{0.115} \\
\hline No & $11(26.2)$ & $2(25)$ & \\
\hline
\end{tabular}

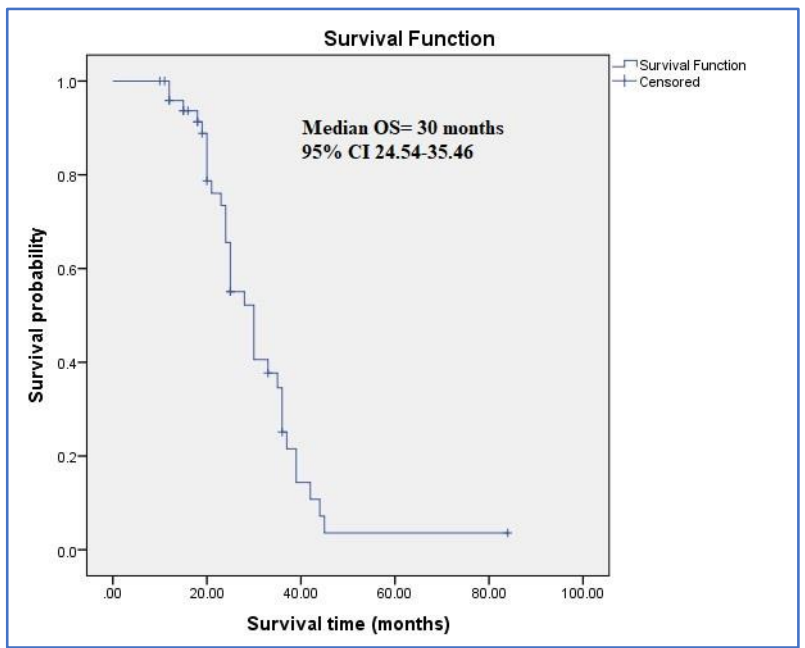

Figure 1: Kaplan Meier curve showing overall survival of all patients
Table 3: Univariate analysis of overall survival in $\mathbf{5 0}$ patients with multiple myeloma

\begin{tabular}{|c|c|c|c|}
\hline Variable & $\begin{array}{l}\begin{array}{l}\text { Median OS } \\
\text { (months) }\end{array} \\
\end{array}$ & $95 \% \mathrm{CI}$ & $\begin{array}{l}\text { p- } \\
\text { value }\end{array}$ \\
\hline \multicolumn{4}{|l|}{ Age (years) } \\
\hline$\geq 65$ & 30 & $17.58-42.41$ & \multirow[t]{2}{*}{0.501} \\
\hline$<65$ & 28 & $23.97-32.03$ & \\
\hline \multicolumn{4}{|l|}{ Sex } \\
\hline Male & 25 & $17.07-32.92$ & \multirow[t]{2}{*}{0.152} \\
\hline Female & 30 & $26.42-33.57$ & \\
\hline \multicolumn{4}{|l|}{ Stage } \\
\hline I & 36 & $31.89-40.1$ & \multirow[t]{3}{*}{0.019} \\
\hline II & 28 & $23.51-32.48$ & \\
\hline III & 25 & $20.46-29.53$ & \\
\hline \multicolumn{4}{|l|}{ Anemia } \\
\hline Yes & 30 & $23.82-36.17$ & \multirow[t]{2}{*}{0.211} \\
\hline No & 30 & $20.22-39-77$ & \\
\hline \multicolumn{4}{|c|}{ Hypercalcemia } \\
\hline Yes & 35 & $18.71-51.28$ & \multirow[t]{2}{*}{0.712} \\
\hline No & 28 & $23.6-32.29$ & \\
\hline
\end{tabular}

\begin{tabular}{|c|c|c|c|}
\hline \multicolumn{4}{|l|}{$\begin{array}{l}\text { Renal } \\
\text { impairment }\end{array}$} \\
\hline Yes & 25 & $23.39-26.6$ & 0.008 \\
\hline No & 33 & $27.7-38.29$ & \\
\hline \multicolumn{4}{|c|}{$\begin{array}{l}\text { Albumin level } \\
(\mathrm{gm} / \mathrm{L})\end{array}$} \\
\hline$\geq 35$ & 33 & $24.4-41.59$ & 0.215 \\
\hline$<35$ & 25 & $20.2-29.79$ & \\
\hline \multicolumn{4}{|c|}{$\begin{array}{l}\text { B2 } \\
\text { microglobulin } \\
(\mathrm{mg} / \mathrm{L})\end{array}$} \\
\hline$\geq 3.5$ & 25 & $23.76-26.24$ & 0.032 \\
\hline$<3.5$ & 36 & $31.67-40.32$ & \\
\hline \multicolumn{4}{|l|}{$\begin{array}{l}\text { CD56 } \\
\text { expression }\end{array}$} \\
\hline Positive & 30 & $27.36-32.64$ & 0.006 \\
\hline Negative & 24 & $10.14-37.85$ & \\
\hline
\end{tabular}

CI: Confidence interval, OS: Overall survival

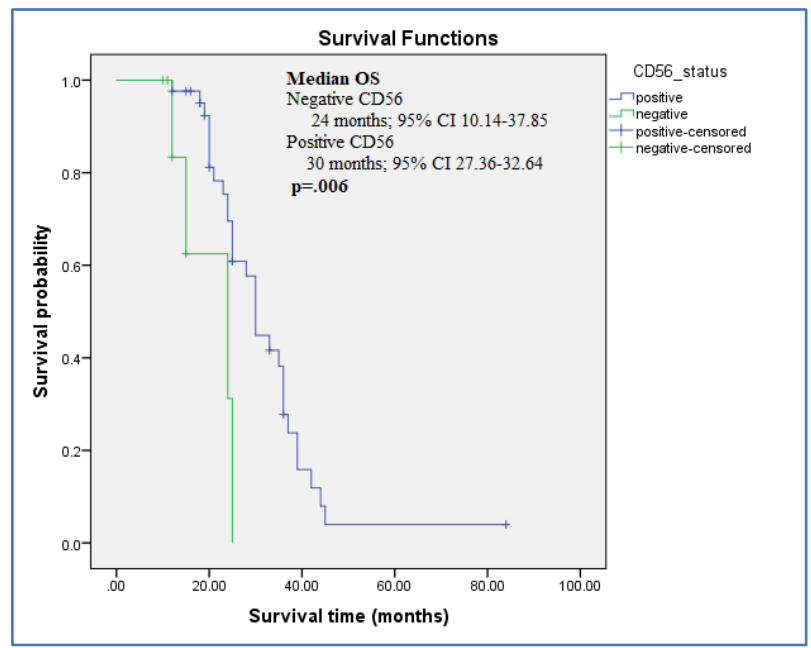

Figure 2: Kaplan Meier curves showing overall survival according to CD56 expression status 
Table 4: Multivariate analysis of overall survival in 50 patients with multiple myeloma

\begin{tabular}{llll}
\hline Variable & HR & 95\% CI & p-value \\
\hline Advanced stage & 1.55 & $0.77-3.11$ & 0.217 \\
\hline No renal impairment & 0.30 & $0.12-0.78$ & 0.014 \\
\hline $\begin{array}{l}\text { Higher B2 } \\
\text { microglobulin }\end{array}$ & 1.05 & $0.28-3.93$ & 0.936 \\
\hline $\begin{array}{l}\text { Negative CD56 } \\
\text { expression }\end{array}$ & 4.31 & $1.23-15.13$ & 0.002 \\
\hline
\end{tabular}

HR: Hazard ratio, CI: Confidence interval

The presence of CD56 has been related to malignancy in plasma cells, and its downregulation has been shown to be associated with high proliferation and spreading of malignant plasma cells ${ }^{9}$. In this study, we found that CD56 expression had no negative effect on the prevalence of clinical manifestations.

In contrast to our results, $\mathrm{Ngo}$ et al stated that the presence of CD56 correlates with the aggressiveness of disease in myeloma patients ${ }^{10}$. Also, Pan et al found that CD56 negativity is associated with a lower frequency of bony lesions, which differs from our finding that CD56 expression status is not associated with a significant change in the incidence of bony lesions.

Unlike the results of our study, Boshnak and Hashem found that CD56 positivity was associated with advanced stage ${ }^{14}$. However, the results of Ceran et al ${ }^{17}$ agree with our results, as CD56 expression was found to have no effect on clinical behavior. Such discrepancies may be attributed to differences in the sample size.

The lack of expression of CD56 was found to be an independent poor prognostic factor, which confirms the findings of other studies $11,15,18$. Overall survival was significantly reduced in patients having negative CD56 disease when compared to those with positive CD56. This finding is consistent with the findings of Skerget et al who found that lack of CD56 expression is a bad prognostic factor in patients with MM even with bortezomib induction ${ }^{18}$. Of note, they estimated the prognostic value of CD56 expression in relation to progression-free survival, not overall survival as in our study. Also, our results agree with that reported by Qiu et al who that the OS of CD56 positive patients is significantly better than that of CD56 negative patients (53 months vs 31 months, respectively; $p=0.016)^{15}$.

The limitations of our study include the small sample size, being a single center one and its retrospective design. In addition, we did not include other known prognostic factors in MM, like lactate dehydrogenase (LDH) serum level.

\section{Conclusion}

The present study suggests that CD56 negativity is associated with poor prognosis in patients with MM, independently of other factors.

The incorporation of CD56 in risk stratification of MM patients may be considered.

Further prospective studies with larger sample are needed to validate its prognostic role.

\section{CONFLICT OF INTEREST}

The authors have no conflict of interest to disclose.

\section{REFERENCES}

1. Manier S, Avet-Loiseau H, Campigotto F, et al. Circulating exosomal microRNAs are critical prognostic markers independent of cytogenetics and International Staging System in Multiple Myeloma. Clin Lymphoma Myeloma Leuk. 2015; 15: e47-e48.

2. Raja KR, Kovarova L, Hajek R. Review of phenotypic markers used in flow cytometric analysis of MGUS and $\mathrm{MM}$, and applicability of flow cytometry in other plasma cell disorders. Br J Haematol. 2010; 149(3): 334-351.

3. Lin P, Owens R, Tricot G, Wilson CS. Flow cytometric immunophenotypic analysis of 306 cases of multiple myeloma. Am J Clin Pathol. 2004; 121(4): 482-488.

4. Robillard N, Wuillème S, Moreau P, Béné MC. Immunophenotype of normal and myelomatous plasma-cell subsets. Front Immunol. 2014; 5: 137.

5. Kumar S, Kimlinger T, Morice W. Immunophenotyping in multiple myeloma and related plasma cell disorders. Best Pract Res Clin Haematol. 2010; 23(3): 433-451.

6. Rawstron AC, Orfao A, Beksac M, et al. Report of the European Myeloma Network on multiparametric flow cytometry in multiple myeloma and related disorders. Haematologica. 2008; 93(3): 431-438.

7. Kraj M, Sokołowska U, Kopeć-Szlęzak J, et al. Clinicopathological correlates of plasma cell CD56 (NCAM) expression in multiple myeloma. Leuk Lymphoma. 2008; 49(2): 298-305.

8. Flores-Montero J., de Tute R., Paiva B, et al. Immunophenotype of normal vs. myeloma plasma cells: Toward antibody panel specifications for MRD detection in multiple myeloma. Cytometry B Clin Cytom. 2016; 90(1): 61-72.

9. Pellat-Deceunynck C, Barillé S, Jego G, et al. The absence of CD56 (NCAM) on malignant plasma cells is a hallmark of plasma cell leukemia and of a special subset of multiple myeloma. Leukemia. 1998; 12(12): 1977-1982.

10. Ngo NT, Brodie C, Giles C, et al. The significance of tumour cell immunophenotype in myeloma and its impact on clinical outcome. J Clin Pathol. 2009; 62(11): 10091015.

11. Pan Y, Wang H, Tao Q, et al. Absence of both CD56 and CD117 expression on malignant plasma cells is related with a poor prognosis in patients with newly diagnosed multiple myeloma. Leuk Res. 2016; 40: 77-82.

12. Rajkumar SV, Dimopoulos MA, Palumbo A, et al. International Myeloma Working Group updated criteria for the diagnosis of multiple myeloma. Lancet Oncol. 2014; 15(12): e538-548.

13. González-Calle V, Slack A, Keane N, et al. Evaluation of Revised International Staging System (R-ISS) for transplant-eligible multiple myeloma patients. Ann Hematol. 2018; 97(8): 1453-1462.

14. Boshnak, NH, Hashem, AE. Association between immunophenotypic markers and cytogenetic aberrations in Egyptian patients with plasma cell myeloma. Egypt J Haematol. 2017; 42(1): 1.

15. Qiu Q, Zhu P, Wang MJ, et al. Expression of CD56 and CD19 in patients with newly diagnosed multiple myeloma and their relationship with karyotypes and prognosis. Zhongguo Shi Yan Xue Ye Xue Za Zhi. 2016; 24(4): 10711078.

16. Shim H, Ha JH, Lee H, et al. Expression of myeloid antigen in neoplastic plasma cells is related to adverse prognosis in 
patients with multiple myeloma. BioMed Res Int. 2014; 2014: 893243.

17. Ceran, F, Falay M, Dağdaş S, Özet G. The assessment of CD56 and CD117 expressions at the time of the diagnosis in multiple myeloma patients. Turk J Haematol. 2017; 34(3): 226-232.
18. Skerget M, Skopec B, Zadnik V, et al. CD56 expression is an important prognostic factor in multiple myeloma even with bortezomib induction. Acta Haematol. 2018; 139(4): 228-234. 